\title{
Comunicação organizacional e desinformação: uma reflexão sobre comunicação pública no Brasil durante a pandemia da covid-19
}

Organizational communication and disinformation: a reflection on public communication in Brazil during the COVID-19 pandemic

Comunicación organizacional y desinformación: una reflexión sobre la comunicación pública en Brasil durante la pandemia del covid-19

\section{Maria Lívia Pacheco de OLiveira}

- $\quad$ Professora do Programa de Pós-Graduação em Ciência da Informação da Universidade Federal de Alagoas (Ufal) e do curso de Relações Públicas da Universidade Federal da Paraíba (UFPB).

- $\quad$ Doutora e mestre em Ciência da Informação pela UFPB.

- Bacharel em Relações Públicas pela UFPB.

- $\quad$ E-mail: maria.livia@academico.ufpb.br

\section{(9) Caroline Delevati Colpo}

- Professora do Programa de Pós-Graduação em Comunicação e Culturas Midiáticas e do curso de Relações Públicas da UFPB.

- Doutora em Comunicação Social pela Pontifícia Universidade Católica do Rio Grande do Sul (PUC-RS).

- Mestre em Desenvolvimento Regional pela Universidade de Santa Cruz (Unisc)

- Graduada em Relações Públicas pela Universidade Federal de Santa Maria (UFSM).

- E-mail: caroline.colpo@academico.ufpb.br 


\section{Resumo}

Neste artigo, discute-se os conceitos de comunicação, informação e desinformação aplicados à comunicação organizacional de caráter público, no que tange à confiança organizacional. Por meio de uma pesquisa exploratória qualitativa, objetivase analisar um levantamento sobre desinformação do início da pandemia da covid-19 no Brasil, traçando uma relação com comunicações públicas realizadas nesse período. Conclui-se que a comunicação organizacional pública não pautada na ética contribui negativamente para a confiança das organizações, além de poder ser utilizada na formatação de desinformação.

\section{PALAVRAS-CHAVE: COMUNICAÇÃO ORGANIZACIONAL・DESINFORMAÇÃO • CONFIANÇA ORGANIZACIONAL.}

\section{Abstract}

This article discusses the concepts of communication, information and disinformation applied to organizational public communication, regarding organizational trust. This article aims to analyze, by a qualitative exploratory research, data on disinformation about the beginning of the COVID-19 pandemic in Brazil, drawing a relationship with public communications carried out in this period. We concluded that public organizational communication not based on ethics contributes negatively to the trust of organizations, and can be used to create disinformation.

\section{KEYWORDS: ORGANIZATIONAL COMMUNICATION•DISINFORMATION・ORGANIZATIONAL TRUST.}

\section{Resumen}

En este artículo se analizan los conceptos de comunicación, información y desinformación aplicados a la comunicación organizacional de carácter público, con respecto a la confianza organizacional. Su objetivo desde una investigación exploratoria cualitativa fue conocer el grado de desinformación desde el comienzo de la pandemia del covid-19 en Brasil analizando los contenidos de las comunicaciones públicas en este periodo. Se concluye que la comunicación organizacional pública que no está basada en la ética contribuye negativamente a la confianza de las organizaciones, además de ser utilizada para difundir la desinformación. 


\section{UM CONTEXTO DA COMUNICAÇÃO, INFORMAÇÃO, DESINFORMAÇÃO E COMUNICAÇÃO PÚBLICA}

A comunicação se modifica rapidamente, enquanto ato humano e animal, enquanto ciência e enquanto saber. Se a sociedade se movimenta, a comunicação se movimenta e também se modifica. Para Amado (2019, p.241), "[...] la comunicación es una institución tan antigua como las comunidades humanas pero sus reglas no son las de entonces porque cambian al ritmo de las transformaciones de la sociedad".

Por isso, a área de pesquisa da comunicação precisa compreender a necessidade de conviver com sua imprecisão conceitual, assumindo o seu caráter polissêmico' e sua constante modificação que inclusive afeta conceitos. Assim, frente a essa variedade, deve-se sempre empreender discussões suscitadas pela pergunta: "[...] de que comunicação e informação se fala?" (Martino, 2001).

Segundo Wolton (2004, p.27), "[...] a comunicação é um dos mais brilhantes símbolos do século XX; seu ideal de aproximar os homens, os valores e as culturas compensa os horrores e as barbaridades de nossa época". A comunicação é transversal ao homem e a suas formas de socialização, pois usa, como conteúdo, a cultura, a política, as organizações e tudo que possa se (re)construir, enquanto contexto social, por meio de elementos simbólicos².

No pensamento de Wolton (2004), admite-se que a comunicação pode consistir em comunicação direta ou comunicação técnica ${ }^{3}$. A comunicação direta é, inicialmente, uma experiência antropológica, em que comunicar-se é compartilhar com 0 outro. Martino (2001) refere-se aos processos de comunicação como forma de compartilhar um mesmo objeto de consciência, em que os sujeitos se comunicam para se constituírem individual e coletivamente. Nesse contexto, "não há seres humanos sem sociedade, como não há sociedade sem comunicação [...]" (Wolton, 2004, p.30), entretanto, existem diferentes padrões de comunicação interpessoais e coletivos, que contemplam formas distintas de apropriação dos elementos simbólicos e de (re)significação. Segundo Wolton (2004, p.30), toda comunicação está ligada a um padrão cultural estabelecido:

Ou seja, a uma representação do outro, porque comunicar consiste em difundir, mas também interagir com um indivíduo ou uma coletividade. 0 ato banal da comunicação condensa em realidade a história de uma cultura e de uma sociedade.

A comunicação direta pode ser compreendida como a relação estabelecida entre dois ou mais sujeitos, na qual um sujeito compartilha alguma coisa, dando-lhe significado, e o outro gera seu significante, buscando sempre relação social e interação (Wolton, 2010). Entender a comunicação direta abrange, portanto, refletir sobre a necessidade de administrar as diferenças inerentes às sociedades em processo de globalização, por meio da renovação dos aspectos contemporâneos dos laços sociais. Hoje, os laços sociais ${ }^{4}$ mantêm

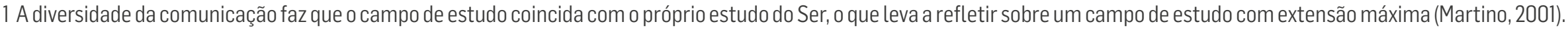

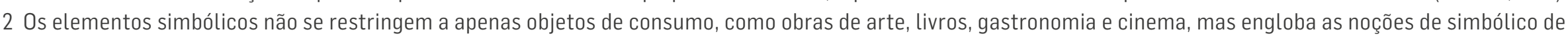

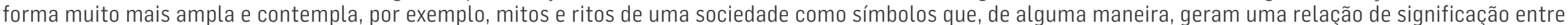

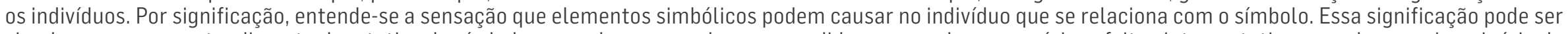

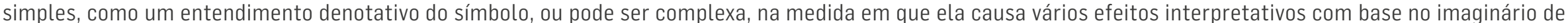

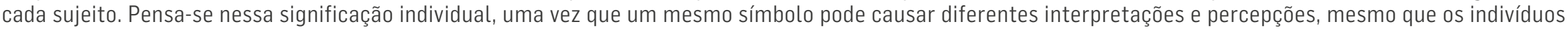

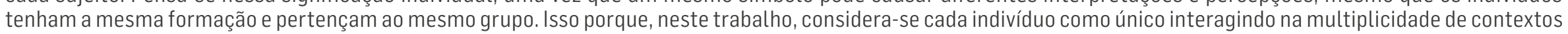
(Canclini, 2007; Morin, 2008).

3 Wolton (2004) ainda considera a comunicação social, que não será abordada neste trabalho.

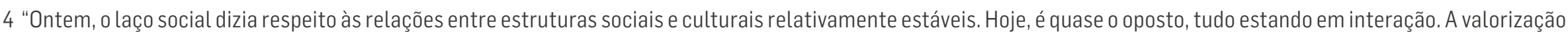

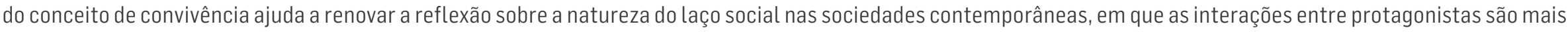
numerosas e contraditórias" (Wolton, 2010, p.25) 
ligados, em uma sociedade, grupos, indivíduos e comunidades, mas de formas contraditórias. 0 laço social, ao mesmo tempo, mantém o local e cria relação com o global; cria identidade enquanto possibilita a abertura de outras formas de identificação.

A comunicação entendida como técnica (Wolton, 2004) tem gradativamente substituído a comunicação direta, de forma mais acelerada na comunicação digital, especialmente em redes sociais. A comunicação técnica transcende a forma direta entre duas ou mais pessoas; trata-se da comunicação mediatizada com a utilização de técnicas, em especial da comunicação à distância. Os aparatos tecnológicos, como telefone, internet, rádio e televisão, têm grande relevância na sociedade enquanto formas técnicas do processo comunicativo e, segundo Wolton (2004), comunicar-se instantaneamente com todos os lugares do mundo por meio das técnicas disponíveis tornou a comunicação uma banalidade.

Em 2010, Wolton reconsidera seu entendimento de comunicação técnica e a admite como informação, isto é, como a transmissão de alguma coisa que lhe dá forma e significado. De acordo com Martino (2001), toda informação pressupõe um suporte técnico, com certos materiais e um código no qual é elaborada a informação. Então, a informação passa a ser entendida como a possibilidade de dar forma a traços materiais, por meio da organização desses traços. Quando esses traços materiais organizados, ou seja, a informação, coloca duas ou mais consciências em relação (Martino, 2001) por meio dos laços sociais, pode-se ter, então, a efetivação de alguns processos de comunicação, isto é, a comunicação só existe com a informação devidamente organizada. Para Martino (2001), não há comunicação sem informação e não há informação senão em vista da possibilidade de ela se tornar comunicação.

Os traços materiais para a criação de algumas informações podem ser usados distintamente, devido aos diferentes tipos de organizações e à diversidade de sujeitos. A habilidade em lidar com a informação, especialmente por meios digitais, configurase como um tipo de information literacy (American Library Association [ALA], 2000) ou competência em informação, que, a priori, permite que os sujeitos transitem na complexa rede de informações de maneira mais ordenada, reconhecendo suas necessidades, buscando, avaliando, reconstruindo, debatendo e compartilhando informação de forma contextualizada, com sua própria realidade e suas formas de significação.

Esse é um cenário ideal não facilmente obtido, pois as formas de comunicação e a quantidade e qualidade da informação refletem nos cenários sociais, educacionais e econômicos de determinada sociedade. Quanto mais acentuadas as desigualdades sociais e menos elevado o nível de educação formal, maiores são as dificuldades no uso da informação, o que aumenta os problemas de comunicação entre os sujeitos e contribui para a formação de um espaço desordenado e caótico.

A desordem da informação pode ser entendida como o resultado das múltiplas transgressões aplicadas à informação, que a tornam divergente da informação considerada legítima e verdadeira com base em parâmetros legítimos, como a história, os fatos, o contexto e a ciência. Segundo Wardle e Derakhshan (2017), a desordem da informação distribui-se em três grandes grupos: mis-information, mal-informatione dis-information. Mis-information (informação incorreta) é uma falsa informação que não tem a intenção primeira de assim ser ou de causar danos; mal-information (má informação) é a informação considerada legítima, mas descontextualizada ou utilizada, propositalmente, como ofensa ou insulto; e dis-information (desinformação) é a informação deliberadamente enganosa ou comprovadamente falsa, elaborada especificamente para um propósito nocivo, a exemplo das fake news.

As falhas mais comuns nos processos de comunicação incluem falta de assertividade, de clareza e de direcionamento aos públicos, bem como dois problemas ligados à informação: seu excesso ou sua escassez. Esses elementos que dificultam o processo de comunicação tornam-se "matéria-prima" para a criação de desinformação, especialmente quando a comunicação e a informação consideradas originais partem de organizações ou de sujeitos reconhecidos socialmente como autoridades em suas áreas. 
Compreendendo as organizações como um sistema vivo constituído de partes interdependentes entre si, que interagem e se transformam mutuamente (Morin, 1991) por processos de comunicação e de informação, entende-se que as organizações não estão livres e isentas de gerar, promover ou incentivar a desinformação. Sob essa perspectiva, a noção de comunicação organizacional necessita ser percebida como viva, capaz de transformar e de ser transformada por meio dos laços sociais e das possíveis identificações de elementos simbólicos dos sujeitos envolvidos no processo de comunicação e informação que, na maioria das vezes, extrapolam os domínios organizacionais. Para tal, a comunicação organizacional deve abranger todas as formas de comunicação e de informação utilizadas e desenvolvidas pela organização para tentar se relacionar e interagir com seus sujeitos, com a ciência de que, nos laços sociais, a compreensão da informação emitida pelas organizações pode causar efeitos nem sempre esperados. Isso acontece muitas vezes porque, em uma mesma organização, há uma pluralidade de sujeitos, cada um dos quais é, ao mesmo tempo, singular e coletivo. De acordo com Freitas (2000, p.87), "[...] somos ao mesmo tempo um individual e um coletivo, um sozinho e uma multidão, um ninguém e um todo-mundo, que se apresenta e representa nas relações múltiplas do cotidiano". Mesmo sendo individual e/ou coletivo, os sujeitos tornaram-se coadjuvantes no processo de comunicação e de informação do contexto organizacional.

Nesse sentido, a comunicação organizacional precisa compreender tudo aquilo que é processado pela própria organização, assim como todos os possíveis desdobramentos dos processos de comunicação e de informação, inclusive a desinformação. É necessário que as estratégias de informação existentes nas organizações transcendam o pensamento instrumentalista para dar espaço aos processos de comunicação fundamentados também nos elementos simbólicos de seus sujeitos. Em tempos de desinformação, as possibilidades de compreensão da comunicação organizacional não podem ser regidas exclusivamente pelas lógicas de mercado, sendo simplificadas apenas na aplicação de instrumentos em busca de resultados imediatos. Isso gera uma visão reducionista da comunicação organizacional e atribui à organização toda a responsabilidade de constituição de seu poder simbólico criado, considerando que o sujeito receptor é pouco ativo. É preciso admitir que o sujeito é capaz de (re)construir os significados da organização, por meio de processos de comunicação, e de recriar o significado delas.

Essa comunicação organizacional precisa ser repensada por organizações privadas, por organizações do terceiro setor e também por organizações de caráter público. Apesar disso, o desdobramento da comunicação organizacional de caráter público está diretamente relacionado à eficácia da comunicação pública na disponibilização de informação sobre processos de gestão que são indispensáveis para viabilizar a discussão democrática pautada em dados confiáveis e, principalmente, servir de evidência para o enfrentamento aos produtos indesejáveis da desinformação. Com a finalidade de efetivar a comunicação pública, foi promulgada, no Brasil, a Lei de Acesso à Informação (Lei n-12.527), de 18 de novembro de 2011, segundo a qual organizações do poder público precisam assegurar a gestão transparente da informação para o cidadão brasileiro. Para isso, torna obrigatória a divulgação de dados de interesse da população como forma de assegurar processos democráticos (Brasil, 2011).

Muitos países atribuem a capacidade de manter seus processos democráticos à forma como realizam sua governança ${ }^{5}$, ao gerenciamento de recursos públicos e, principalmente, ao incentivo à maior interação entre sujeitos e organizações públicas, o que, por sua vez, pode gerar mais confiança. Labarca e Rojas (2017, p.535) apontam que "[...] la confianza se asocia a la comunicación" e que, quando o processo de comunicação está debilitado, traz consequências na construção da confiança (Labarca; Rojas, 2017, p.535). Na efetivação da comunicação pública, a interação entre os sujeitos por meio da informação disponibilizada de forma clara e acessível, faz que se tenha mais ou menos confiança nas organizações de caráter público.

Para Novelli (2006), a comunicação pública pode ser compreendida como o processo de comunicação entre as organizações públicas e a sociedade que objetiva promover a troca ou o compartilhamento de informações de interesse público. Considerando esse processo,

5 A governança se refere à forma adotada pelo Estado para implementar seus projetos ou, ainda, aos pré-requisitos institucionais para a otimização do desempenho administrativo - instrumentos técnicos de gestão que assegurem a eficiência e a democratização das políticas públicas (Novelli, 2006). 
infere-se que órgãos públicos deveriam usar processos de comunicação organizacional para dar visibilidade a temas de interesse público, baseados em fatos reais e com comprovação técnica e científica, para que se torne possível gerar confiança organizacional.

Matos (2006) aponta que a compreensão da comunicação pública não pode ser considerada uma ação isolada de governos, das organizações ou da própria mídia, mas deve ser entendida como resultado do envolvimento dos sujeitos com assuntos públicos. Criar essa relação gera confiança nas organizações públicas e possibilita a continuidade das interações efetivas entre Estado e sociedade. Essa via permite que a comunicação pública possa avançar por um caminho próprio e efetivo (Matos, 2006). Weber (2017) reforça a ideia de Matos (2006) ao considerar que temas de interesse público circulam enquanto os implicados (sociedade e governo) os mantêm visíveis, por meio de processos de exigência, de colaboração ou de recusa de determinadas ações e sobre acontecimentos públicos.

Mesmo assim, o que ocorre na maioria das vezes, ainda considerando as exigências da Lei de Acesso à Informação (Brasil, 2011), é a percepção de apenas uma disseminação da informação, com os traços materiais de construção dessa informação pouco articulados. Isso gera um grau muito baixo de envolvimento da sociedade e não efetiva, de forma alguma, processos comunicativos e confiança, o que torna oportuno o surgimento de desinformação.

\section{INFORMAÇÃO PÚBLICA NO BRASIL: ANÁLISE DA RELAÇÃO ENTRE DISCURSO GOVERNAMENTAL E DESINFORMAÇÃO}

Durante períodos sociais críticos, torna-se comum utilizar uma comunicação direta com a população por parte das organizações públicas. Isso porque há a urgência de obtenção de informação segura, além de a população necessitar que tais organizações públicas personifiquem um responsável por liderar determinada situação. Em meio à pandemia da covid-19, representantes governamentais mundiais estiveram à frente desse tipo de comunicação, promovendo discursos oficiais com o objetivo de informar planos de ação contra a pandemia, incluindo seguridade social e apoio econômico.

Considerando esse contexto, questiona-se: os traços materiais utilizados na formatação da informação pública no Brasil, via discursos oficiais, tendem a gerar comunicações eficazes ou colaboram para o surgimento da desinformação?

A partir da problemática apresentada, este trabalho, de caráter exploratório qualitativo, com técnica bibliográfica e com pesquisa documental, propõe-se a analisar um pronunciamento oficial ${ }^{6}$ realizado pelo Presidente do Brasil, Jair Messias Bolsonaro, veiculado em TV aberta no dia 24 de março de 2020, sobre a pandemia da covid-19. A escolha desse pronunciamento oficial deu-se em virtude de ter sido um dos períodos mais críticos do início da pandemia no Brasil, devido ao fechamento de praticamente todas as organizações consideradas não-essenciais, que gerou resistência por parte da população, além da grande repercussão nacional e internacional das falas proferidas.

Em seguida, realizou-se uma análise documental a partir de um levantamento efetuado pela agência de checagem Lupa ${ }^{7}$, em que constam verificações de notícias e de informações feitas pela própria agência. A partir desse documento, foram selecionadas três checagens de informações que circularam após o referido pronunciamento e que têm ligação com o

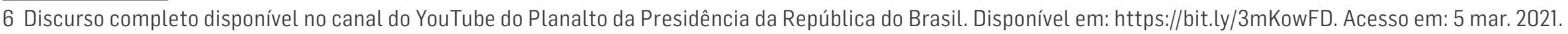

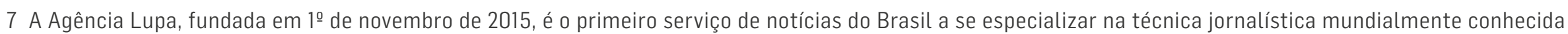

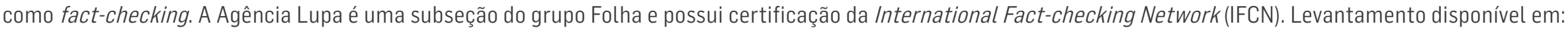
https://bit.ly/3AyJYCm. Acesso em: 5 fev. 2021. 
tema da pandemia ${ }^{8}$. Essa análise cruzada permitiu analisar se havia presença de traços materiais da informação que foram comunicados no pronunciamento e que, possivelmente, serviram de base para a criação de desinformação.

As principais falas do Presidente do Brasil no referido pronunciamento tiveram os objetivos de reduzir o efeito da pandemia, minimizar a gravidade da pandemia da covid-19, defender a volta à suposta normalidade, incentivar o uso de medicamentos sem comprovação científica e criticar a cobertura da mídia sobre o tema.

Para análise, destaca-se o seguinte trecho do pronunciamento oficial do Presidente do Brasil, Jair Messias Bolsonaro, no dia 24 de março de 2020 :

É essencial que o equilíbrio e a verdade prevaleçam entre nós. 0 vírus chegou, está sendo enfrentado por nós e brevemente passará. Nossa vida tem que continuar. Os empregos devem ser mantidos. 0 sustento das famílias deve ser preservado. Devemos, sim, voltar à normalidade. Algumas poucas autoridades estaduais e municipais devem abandonar o conceito de terra arrasada, a proibição de transportes, o fechamento de comércio e o confinamento em massa.

Em 31 de março, após o pronunciamento, circulou pelas redes sociais a informação de que a Organização Mundial da Saúde (OMS) havia recuado nas recomendações de isolamento (Afonso, 2020). Um texto publicado no site Terça Livre ${ }^{9}$ replicou essa informação, afirmando que, para a OMS, "[...] governos devem pensar em quem precisa garantir o pão de cada dia [...]", e veiculou a informação acompanhada de uma imagem de um representante da OMS. A frase, de fato, foi dita pelo mencionado representante, mas com ênfase de que os governos devem prover esses recursos, sem mencionar qualquer ação contrária ao isolamento social. Por isso, a informação foi classificada como falsa, de acordo com extensa análise realizada pela agência Lupa.

Figura 1: Postagem no Facebook de informação publicada pelo site Terça Livre, classificada como mal-information

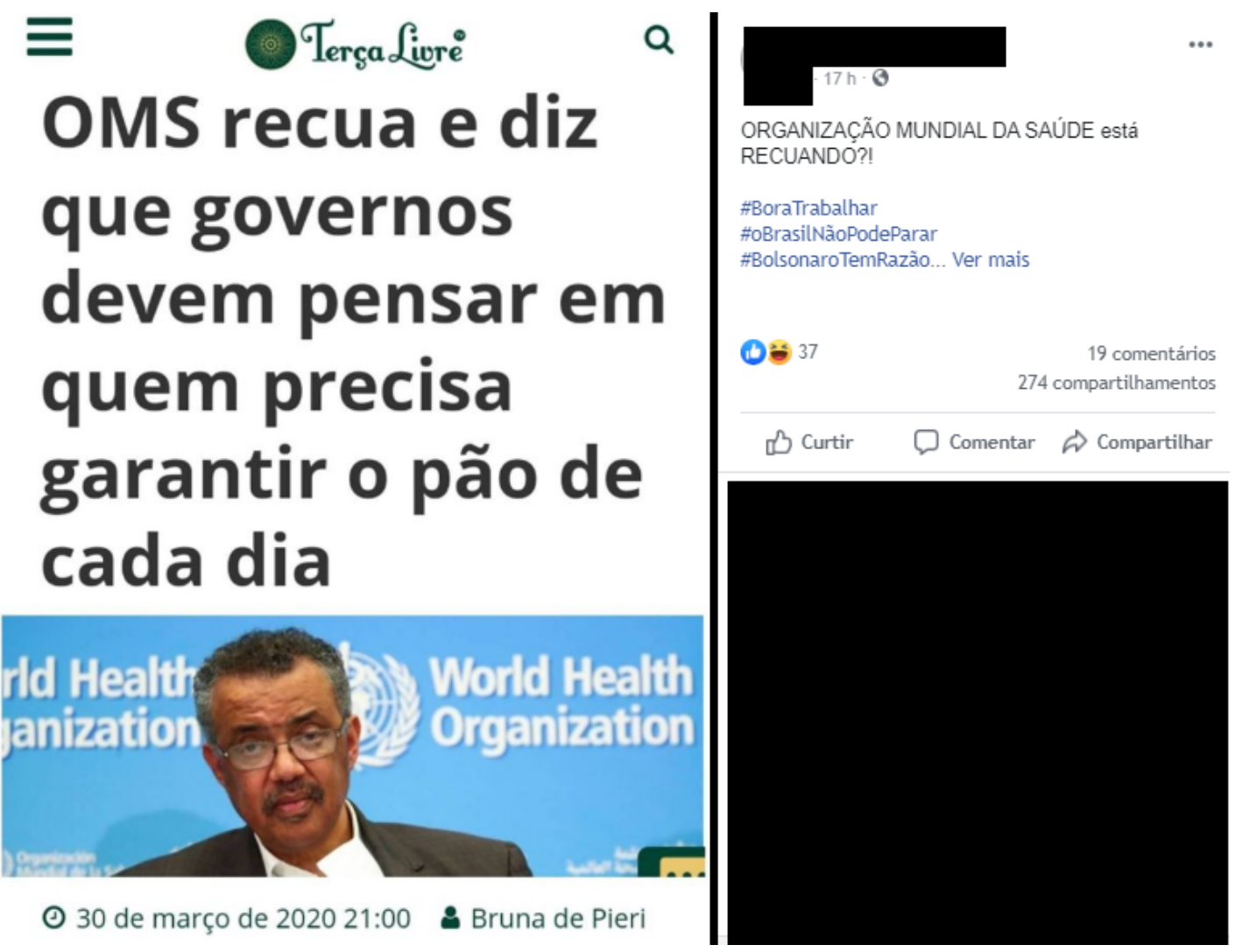

Fonte: Afonso (2020).

8 Entre as inúmeras checagens realizadas pela Agência Lupa, optou-se por escolher as que ilustram diretamente a relação entre as palavras expressas no discurso e os elementos da desinformação gerada. Além disso, a subjetividade do discurso serve de base comum na instauração e na reafirmação de crenças e de emoções compatíveis com o movimento antivacina, por exemplo, que também gera desinformação, muitas vezes, de caráter mais implícito e que exige uma análise mais pormenorizada.

9 Site de notícias conhecido pelo apoio dado ao atual Governo, que se denomina como a extrema-direita do Brasil. 
Nesse caso, observa-se a apropriação de uma informação que fora formalmente proferida por uma autoridade pública, porém, foi retirada de seu contexto e configurou-se como mal-information (Wardle; Derakhshan, 2017). Em seguida, apropriando-se de outros traços informacionais, como dados e imagens, gera-se uma nova informação em formato de notícia, tornando-se um elemento de desinformação. Apesar disso, salienta-se que tal construção informacional e comunicacional (criação de uma notícia e disseminação dela), necessita de um lugar-comum socialmente construído, em que as pessoas possam convergir sobre pensamentos e emoções por meio de seus elementos simbólicos. Como afirma Martino (2001), deve haver o compartilhamento de um mesmo objeto de consciência em prol de manifestações individuais e coletivas. Esse lugar-comum, terreno fértil para desinformação, reúne elementos diversos dentre os quais figuram as organizações, principalmente aquelas de reconhecimento social, como os governos.

A partir do momento em que organizações públicas, por meio de seus representantes maiores, fomentam discursos de grande relevância social, instaura-se um elemento decisivo para gerar um padrão social coletivo. A comunicação está diretamente implicada nesse processo e seu resultado é compatível com os graus de ética, de confiança e de qualidade dos elementos simbólicos proferidos no discurso, isto é, os traços materiais utilizados na formatação da informação podem ser reproduzidos em processos da própria comunicação. Um segundo trecho analisado do discurso presidencial diz que:

Assim fizemos, quase contra tudo e contra todos [sobre manter a normalidade]. Grande parte dos meios de comunicação foi na contramão. Espalharam exatamente a sensação de pavor, tendo como carro-chefe o anúncio do grande número de vítimas na Itália. Um país com grande número de idosos e com um clima totalmente diferente do nosso.

Além de uma postura contrária ao isolamento social, assentada em uma comparação desproporcional e sem respaldo científico com outro país, o trecho analisado criticou o trabalho da mídia, o que impactou diretamente na confiança coletiva sobre as organizações midiáticas. 0 exercício contínuo de combate à desinformação está sendo liderado pela própria mídia e por iniciativas independentes de jornalismo, logo, ao minar a confiança da sociedade quanto ao serviço desempenhado pela imprensa, causa-se perdas no processo de auditabilidade de informações de interesse coletivo.

A comunicação organizacional pública, nesse caso, demonstrou interesse em manter os traços materiais utilizados em suas comunicações distantes da transparência institucional que se esperava, transparência que se manifestaria, por exemplo, expondo a condição do sistema de saúde e defendendo ações de adequação às recomendações da OMS. Essa conduta remonta ao pensamento de Weber (2017), pois ao manter a visibilidade pública de determinada ideia, desde a negação da gravidade da pandemia até a contínua descredibilização da mídia, colabora-se para que as ações e os acontecimentos públicos reforcem tais posicionamentos.

Para exemplificar o ciclo da informação, cita-se que, no dia 4 de abril de 2020, um deputado federal aliado ao governo brasileiro veiculou a seguinte informação nas redes sociais: "Insisto que a quarentena aumenta os casos do coronavírus. A curva da epidemia nos países que a adotaram mostra isso [...]. Isso porque o contágio se transfere da rua para dentro de casa e fica mais fácil" (Marés, 2020). 0 texto era acompanhado de um gráfico e foi replicado 3,6mil vezes até a realização da checagem. 
Figura 2: Postagem no Twitter do deputado federal Osmar Terra, classificada como mal-informatione dis-information

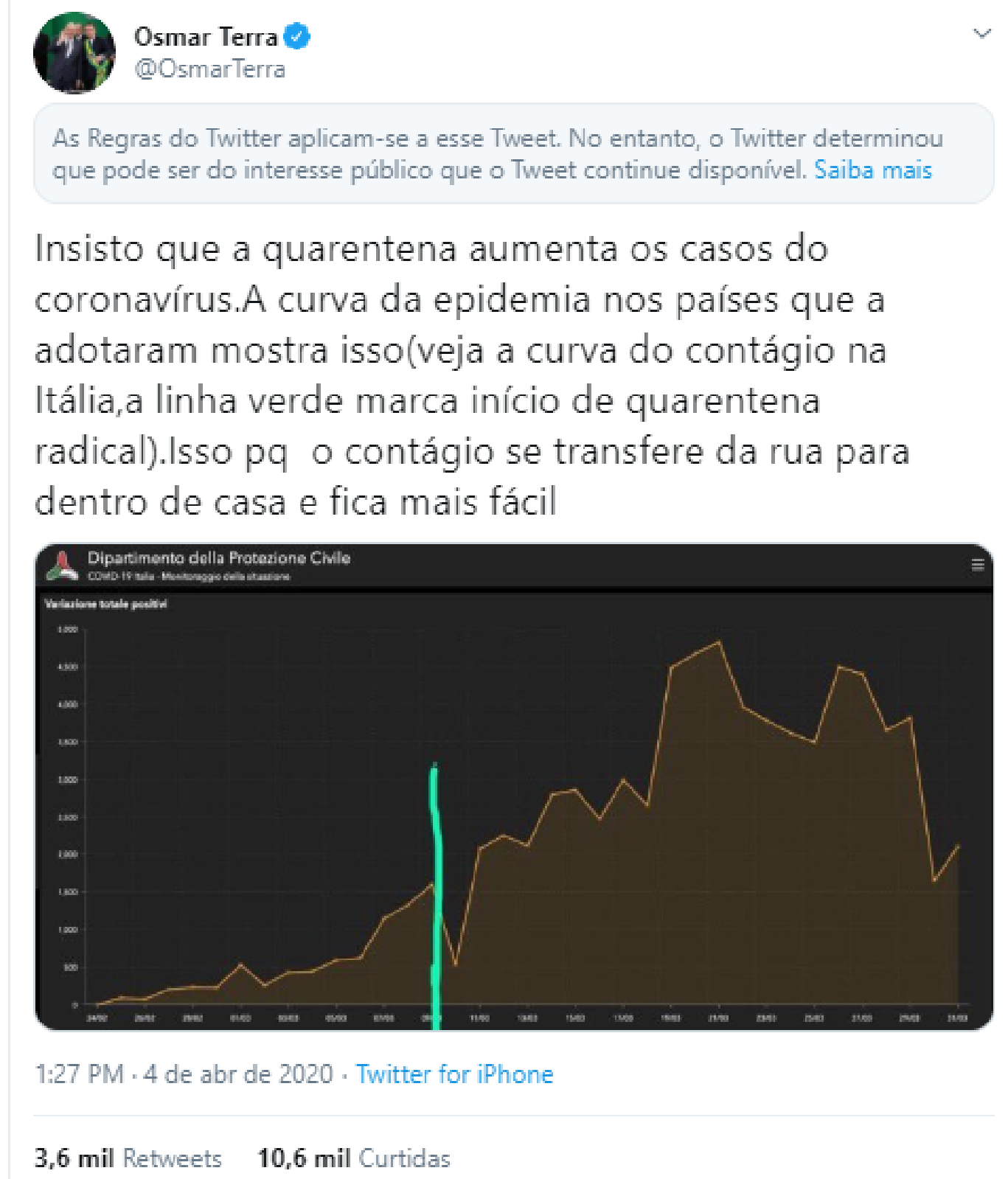

Fonte: Marés (2020).

A agência de checagem Lupa realizou uma análise minuciosa do texto e do gráfico, concluindo que a informação era comprovadamente falsa, uma mescla de mal-information, por ter dados reais, com dis-information (Wardle; Derakhshan, 2017), por acrescentar informações nocivas de forma deliberada a causar danos ao debate público.

Outra passagem do discurso do Presidente diz que:

0 que se passa no mundo tem mostrado que o grupo de risco é o das pessoas acima dos 60 anos. Então, por que fechar escolas? Raros são os casos fatais de pessoas sãs, com menos de 40 anos de idade. Noventa por cento de nós não teremos qualquer manifestação, caso se contamine.

0 discurso manteve-se similar em toda a duração e repetiu as principais ideias com dados sem as devidas fontes comprobatórias. Em 4 de maio, circulou por aplicativos mensageiros um texto com o seguinte título: "Registros de cartórios comprovam: não há epidemia" (Moraes, 2020). 0 texto seguia trazendo dados sobre números de óbitos em cartórios comparados ao número de mortes divulgado por secretarias estaduais de saúde. Parte dos dados eram verdadeiros, porém, estavam descontextualizados (mal-information) e mesclados com conteúdo falsos, de acordo com a análise realizada. 
Figura 3: Print de mensagem do WhatsApp classificada como desinformação

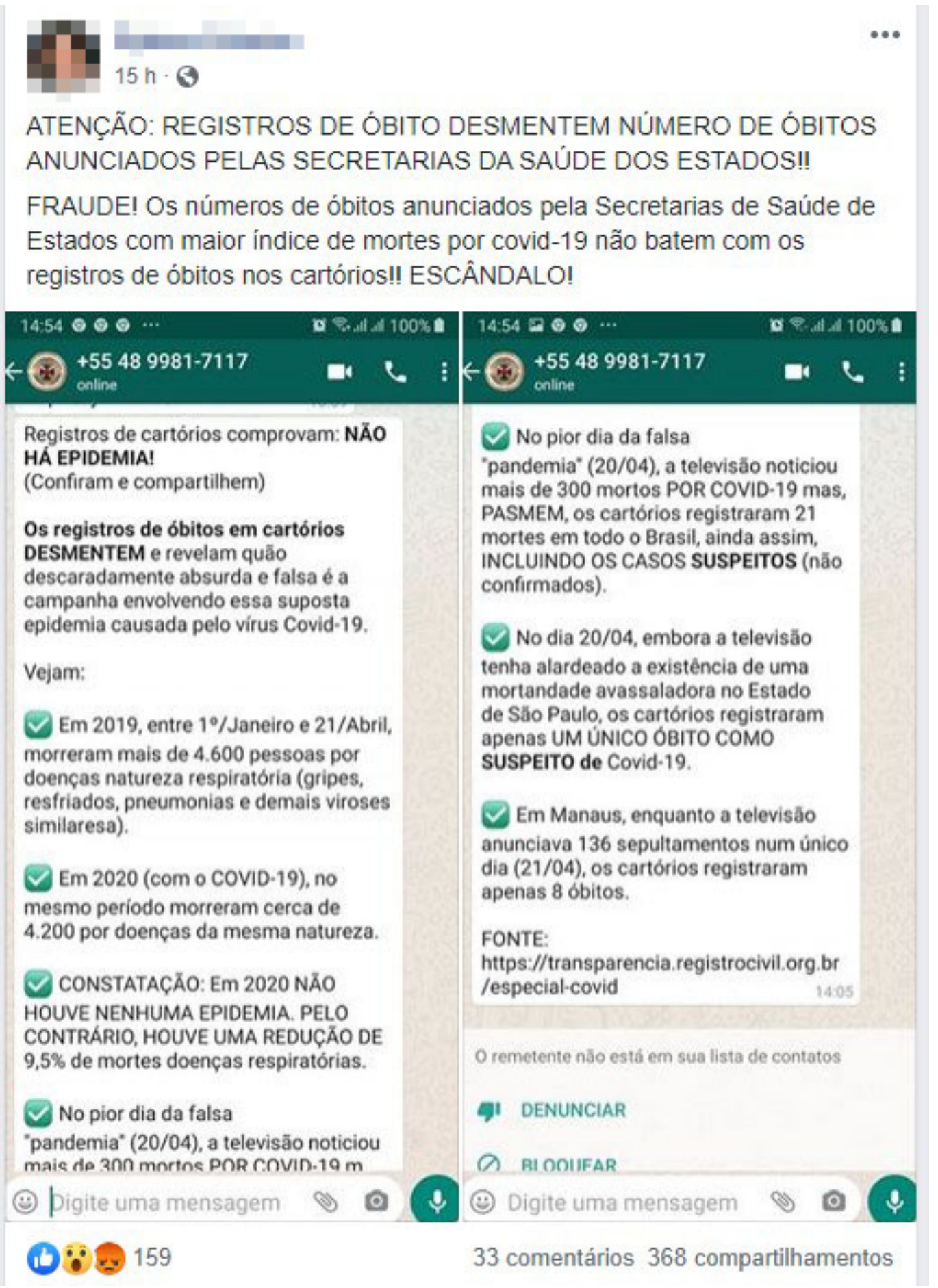

Fonte: Moraes (2020).

Esse último exemplo de desinformação (Figura 3) é ilustrativo quanto ao fator de reprodução e de disseminação da informação via meios digitais de comunicação. Inicialmente, a mensagem circulou por aplicativo de mensagem e, depois, foi reproduzida na rede social Facebook, como a verificação da Lupa informou. Nesta última rede social, teve um número de compartilhamentos relativamente baixo, todavia, desconhece-se seu alcance antes de ali ser postada. Texto em post do Facebook que, até às $17 \mathrm{~h}$ do dia 4 de maio de 2020, tinha 374 compartilhamentos.

É importante observar a característica da desinformação de percorrer diferentes meios, pois isso sinaliza a necessidade de a comunicação organizacional também considerar, em suas práticas comunicacionais, a abordagem dada pelo interesse público a todos os elementos infocomunicacionais, pois,

En la comunicación intervienen los mismos códigos de significación que esquemas de circulación; regulaciones pragmáticas de habla y reglas fonológicas inscritas en contextos de acción e interpretación; performatividad enunciativa y corporal; actos de habla ilocutivos y perlocutivos; acción intencional y operaciones triviales. En todos estos casos, junto con el sistema y la 
cultura se configura un plexo que hace imposibles las interpretaciones lineales, ya sean de interés ejecutivo o de comprensión. (Gonzáles; García, 2019, p.78)

Como afirma Weber (2017), a maneira como os discursos são elaborados, os temas e atores envolvidos e as motivações e as estratégias utilizadas interferem diretamente no debate público, ampliando ou reduzindo sua ação, bem como sua circulação na mesma esfera.

Uma vez que o modelo de participação ativa do cidadão pressupõe um processo de comunicação horizontal, baseado na parceria e no estímulo ao engajamento da sociedade na formulação de políticas públicas (Novelli, 2006), as tecnologias digitais da informação e de comunicação, que privilegiam uma maior interação entre as pessoas independentemente de suas localizações geográficas, podem ser ferramentas valiosas para a viabilização da participação mais ativa do cidadão na comunicação pública e, por consequência, na efetivação de uma maior governança no processo democrático. Mesmo assim, essas ferramentas perdem sua validade quando se tornam meios de criação e disseminação de desinformação, de forma ainda mais potencializada se os traços materiais utilizados tiverem sido dispostos pelas próprias organizações públicas.

Nos três exemplos de desinformação analisados, percebe-se que há uma base comum, que visa a corroborar os ideais proferidos verbalmente pelo Presidente do Brasil. É importante salientar que, após o discurso proferido, houve uma efervescência sobre o tema: gerou-se pautas nas mídias, movimentações nas redes sociais, novos pronunciamentos de parlamentares e de pessoas públicas influentes, entre outras repercussões. Por conseguinte, o pronunciamento reverbera continuamente, semanas e meses após sua execução, pois suas ideias e crenças receberam apoio, reforçando o ciclo de desinformação que perdura ao longo do tempo. Isso remonta ao pensamento de Weber (2017) e Matos (2006) sobre a circulação de temas de interesse público por meio da colaboração dos sujeitos enquanto indivíduos e enquanto um coletivo.

A desinformação tem como pressuposto um lugar compartilhado de elementos simbólicos, construídos por crenças, ideias e sentimentos coletivos que, ao serem estimulados, transformam-se em cenário de desordem informacional (Wardle; Derakhshan, 2017) e, consequentemente, social, principalmente se essa incitação partir de uma figura com poder constituído, como um Presidente de Estado.

\section{CONSIDERAÇÕES FINAIS}

Informações oficiais e públicas cujo acesso é irrestrito para os sujeitos são fundamentais para aperfeiçoar os processos de discussão pública e de política na democracia e para aumentar a confiança dos cidadãos em relação aos seus governos. Apesar disso, caso não se observem as premissas democráticas, o uso indevido das tecnologias da informação pode se tornar instrumento para hegemonias antidemocráticas e elitizadas (Brito, 2006), principalmente quando se trata de uma sociedade polarizada politicamente, como é o caso do Brasil, que tem enfrentado, nos últimos anos, sérias questões sociais, muitas delas derivadas do despreparo coletivo para lidar com a informação e com a comunicação, resultando em índices alarmantes de desinformação.

As falas oficiais de representantes de organizações públicas, mesmo que não sejam éticas e transparentes, fazem que o processo de comunicação se efetive. Os interlocutores, em suas diferentes possibilidades de interpretação e de reconstrução das informações, podem endossar a geração de desinformação a partir dos traços materiais frágeis dispostos nas falas públicas proferidas.

No caso específico do Brasil, a Lei de Acesso à Informação, que prevê traços materiais fortes e seguros, fragiliza-se com outros processos de comunicação pública que deslegitimam a ética e a segurança de dados e de informações, como no caso do discurso analisado (Brasil, 2011). As organizações públicas, ao apresentarem heterogeneidade nos processos informacionais 
e comunicacionais, atentam contra sua própria fonte de estabelecimento de confiança organizacional, contrapondo ações e polarizando a sociedade entre aqueles que concordam sem questionamentos e outros que tendem a manter um posicionamento contrário ou, ao menos, contestador aos processos comunicacionais públicos.

Ressalta-se o indispensável papel da mídia e das organizações que exercem o trabalho de auditabilidade das informações identificadas como potencialmente danosas à sociedade, não somente as que circulam anonimamente pelo ciberespaço, mas também aquelas provenientes de fontes que deveriam assegurar sua veracidade. Garantir a existência e a atuação ativa da mídia nos processos de checagem de informação deve ser de interesse de todo governo e de qualquer organização que deseja se colocar à prova, em uma ação possivelmente geradora de confiança organizacional.

Dessa forma, os traços materiais utilizados na formatação da informação pública no Brasil, por meio do discurso oficial do Presidente da República aqui analisado, apresentaram características compatíveis com os produtos de desinformação analisados. Assim, considera-se que há relação direta entre a comunicação pública oficial e o surgimento de informação não legítima e propositalmente formatada para manter um conjunto de crenças socialmente compartilhadas por aqueles que têm os mesmos elementos simbólicos de significação de quem proferiu o discurso.

\section{REFERÊNCIAS}

AFONSO, Nathália. \#Verificamos: é falso que OMS mudou de posição sobre restrições de movimento durante pandemia de covid-19. Agência Lupa, Rio de Janeiro, 31 mar. 2020. Disponível em: https://bit.ly/3vxBUkA. Acesso em: 5 fev. 2021.

AMERICAN LIBRARY ASSOCIATION. Information literacy defined. In: Information literacy competency standards for higher education, [S.l.], 22 jan. 2000. Disponível em: https://bit.ly/3AvfAZU. Acesso em: 2 jun. 2021.

AMADO, Adriana. Comunicación pública y medios de comunicación social. In: RAMIREZ, Guzmán Haydeé; ECHENIQUE, Raúl Herrera (org.). Comunicación estratégica: interfaz relacional entre organizaciones y sus stakeholders. Bogotá: Universidad Sergio Arboleda, 2019. p.241-260.

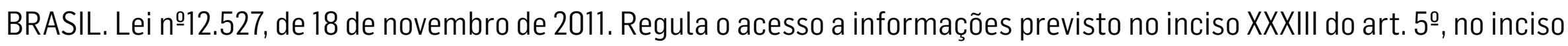

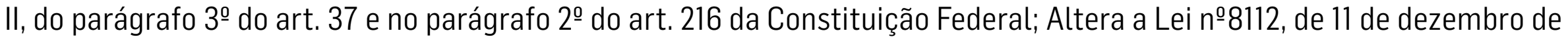
1990; revoga a Lei n-11.111, de 5 de maio de 2005, e dispositivos da Lei n-8.159, de 8 de janeiro de 1991; e dá outras providências. Diário Oficial da União: seção 1, Brasília, DF, p.1, 18 nov. 2011. Disponível em: https://bit.ly/3iRenGa. Acesso em: 12 maio 2021.

BRITO, José Augusto Pereira. Cibercidadania: a virtualização na comunicação pública contemporânea. Organicom, São Paulo, v.3, n.4, p.106-123, 2006. doi: https://doi.org/10.11606/issn.2238-2593.organicom.2006.138914.

CANCLINI, Néstor García. Diferentes, desiguais e desconectados. mapas de interculturalidade. Rio de Janeiro: Editora UFRJ, 2007.

FREITAS, Maria Ester de. Cultura organizacional: sedução e carisma? Rio de Janeiro: Editora FGV, 2000.

GONZÁLEZ, Rafael Ávila; GARCÍA, José Alfredo Andrade. Organização, cultura e comunicação: uma abordagem para opções supradisciplinares. Organicom, São Paulo, v.16, n.30, p.65-81, 2019. doi: https://doi.org/10.11606/issn.2238-2593. organicom.2019.157467. 
LABARCA, Claudia; ROJAS, Rodrigo. Comunicaciones y confianza: ¿información o identidad? El caso del sector vitivinícola chileno hacia el mercado chino. Palabra Clave, Chía, v.20, n.2, p.529-566, 2017. doi: https://doi.org/10.5294/pacla.2017.20.2.10.

MATOS, Heloiza Helena Gomes de. Comunicação Política e Comunicação Pública. Organicom, São Paulo, v.3, n.4, p.58-73, 2006. doi: https://doi.org/10.11606/issn.2238-2593.organicom.2006.138911.

MARÉS, Chico. Análise de Osmar Terra sobre efeitos da quarentena na Itália não tem respaldo científico. Agência Lupa, Rio de Janeiro, 4 abr. 2020. Disponível em: https://bit.ly/2ZaOWKi. Acesso em: 58 fev. 2021.

MARTINO, Luiz C. De qual comunicação estamos falando? In: HOHLFELDT, Antônio; MARTINO, Luiz C.; FRANÇA, Vera Veiga (org.). Teorias da Comunicação: conceitos, escolas e tendências. Petrópolis: Vozes, 2001. p.11-27.

MORAES, Maurício. \#Verificamos: é falso que dados de cartórios "comprovam" que não há pandemia. Agência Lupa, Rio de Janeiro, 4 maio 2020. Disponível em: https://bit.ly/3pswypl. Acesso em: 5 fev. 2021.

MORIN, Edgar. Introdução ao pensamento complexo. Lisboa: Instituto Piaget, 1991.

MORIN, Edgar. O Método IV: as ideias. Porto Alegre: Sulina, 2008.

NOVELLI, Ana Lucia Coelho Romero. 0 papel institucional da comunicação pública para o sucesso da governança. Organicom, São Paulo, v.3, n.4, p.74-89, 2006. doi: https://doi.org/10.11606/issn.2238-2593.organicom.2006.138912.

WARDLE, Claire; DERAKHSHAN, Hossein. Information disorder. toward an interdisciplinary framework for research and policy making. Strasbourg: Council of Europe, 2017. Disponível em: https://bit.ly/3as046n. Acesso em: 20 jan. 2021.

WEBER, Maria Helena. Nas redes de comunicação pública, as disputas possíveis de poder e visibilidade. In: WEBER, Maria Helena; COELHO, Marja Pfeifer; LOCATELLI, Carlos (org.). Comunicação pública e política: pesquisa e prática. Florianópolis: Insular, 2017. p.23-58.

WOLTON, Dominique. Pensar a comunicação. Brasília: Editora UnB, 2004.

WOLTON, Dominique. Informar não é comunicar. Porto Alegre: Sulina, 2010.

Artigo recebido em 29.06.2021 e aprovado em 27.09.2021. 